\title{
Erratum
}

\section{Mann Iteration Converges Faster than Ishikawa Iteration for the Class of Zamfirescu Operators}

\author{
G. V. R. Babu and K. N. V. V. Vara Prasad
}

Received 24 July 2006; Revised 21 September 2006; Accepted 23 October 2006

The aim of this erratum is to make necessary corrections in the proof of Theorem 2.1 of Babu and Prasad (2006).

Copyright (c 2007 G. V. R. Babu and K. N. V. V. Vara Prasad. This is an open access article distributed under the Creative Commons Attribution License, which permits unrestricted use, distribution, and reproduction in any medium, provided the original work is properly cited.

The paper by Babu and Prasad [1] contains some mistakes in the proof of Theorem 2.1. In this erratum, we make the necessary corrections.

We follow the same notation as in [1].

In the statement of Theorem 2.1, we assume that $x_{0}=y_{0} \in K$.

Beginning with (2.1) and applying the technique as in the proof of Theorem 2.1 in [1], we can show that

$$
\left\|x_{n+1}-p\right\| \leq a_{n}\left\|x_{0}-p\right\|
$$

where $a_{n}=\prod_{k=0}^{n}\left[1-\alpha_{k}(1-\delta)\right], n=0,1,2, \ldots$; and also we can show that

$$
\left\|y_{n+1}-p\right\| \leq b_{n}\left\|y_{0}-p\right\|
$$

where $b_{n}=\prod_{k=0}^{n}\left[1-\alpha_{k}(1-\delta)^{2}\right], n=0,1,2, \ldots$

We observe that

$$
\frac{1-\alpha_{k}(1-\delta)}{1-\alpha_{k}(1-\delta)^{2}} \leq 1-\alpha_{k} \delta(1-\delta), \quad k=0,1,2, \ldots
$$


2 Fixed Point Theory and Applications

so that

$$
\frac{a_{n}}{b_{n}} \leq \prod_{k=0}^{n}\left[1-\alpha_{k} \delta(1-\delta)\right], \quad n=0,1,2, \ldots
$$

Thus, $\lim _{n \rightarrow \infty}\left(a_{n} / b_{n}\right)=0$.

Note that $a_{n} \rightarrow 0$ and $b_{n} \rightarrow 0$ as $n \rightarrow \infty$.

\section{Acknowledgments}

The authors are grateful to Professor Xue Zhiqun, for bringing out to the notice of the mistakes in the paper. This work is partially supported by U. G. C. Major Research Project Grant no. F. 8-8/2003 (SR). One of the authors (G. V. R. Babu) thanks the University Grants Commission, India, for the financial support.

\section{References}

[1] G. V. R. Babu and K. N. V. V. Vara Prasad, "Mann iteration converges faster than Ishikawa iteration for the class of Zamfirescu operators," Fixed Point Theory and Applications, vol. 2006, Article ID 49615, 6 pages, 2006.

G. V. R. Babu: Department of Mathematics, Andhra University, Visakhapatnam 530 003, India Email address: gvr_babu@hotmail.com

K. N. V. V. Vara Prasad: Department of Mathematics, Dr. L. Bullayya College, Visakhapatnam 530 013, India

Email address: knvp71@yahoo.co.in 